\title{
Síndrome de Miller Fischer - Relato de caso
}

Laura Zaparoli Zanrosso'; Rodrigo Hirsch Machado²; Andreza Teixeira

Ribeiro ${ }^{3}$; João Augusto Argenton Zortea ${ }^{4}$; Joyce Carvalho Schotten ${ }^{5}$.

\section{RESUMO}

INTRODUÇÃO: A síndrome de Miller Fischer (SMF) é uma desordem rara, caracterizada por oftalmoplegia, ataxia e arreflexia, tendo sido descrita pela primeira vez em 1956. RELATO DE CASO: JSS, 51 anos, feminina, procurou atendimento em emergência com queixa de visão turva e parestesia em membros superiores iniciados há um dia, seguidos de dificuldade na coordenação dos movimentos de início há seis horas. Ao exame físico: paresia de abducente a esquerda, pupilas hipofotoreativas, leve dismetria e marcha atáxica, sem mais dados relevantes. Tomografia de crânio não demonstrou alterações, bem como ressonância magnética com gadolíneo. Três dias após, apresentava estado mental preservado, disartria leve, oftalmoplegia completa a esquerda, oftalmoparesia à direita, ausência de assimetrias faciais, hipoestesia bilateral em face, força preservada em membros inferiores, arreflexia patelar bilateral, Sinal de Hoffmann ausente bilateral, cutâneo plantar em flexão e marcha atáxica. Com hipótese clínica de SMF, realizada punção lombar, com resultado compatível. Considerando achados clínicos e exames complementares, iniciou-se tratamento com uso de imunoglobulina. Paciente apresentou melhora progressiva dos sintomas, recebendo alta hospitalar após 20 dias de internação, com orientação de seguimento ambulatorial. DISCUSSÃO:

\footnotetext{
1 Doutoranda do décimo primeiro semestre da Faculdade de Medicina da Universidade Luterana Interna no estágio em Clínica Médica. Email para contato: laura.zanrosso@hotmail.com. Apresentadora do trabalho.

2 Médico, residente em Cardiologia no Instituto de Cardiologia do Rio Grande do Sul.

3. Doutoranda do décimo primeiro semestre da Faculdade de Medicina da Universidade Luterana Interna no estágio em Clínica Médica. Email para contato: andrezatribeiro@gmail.com

4. Doutorando do décimo primeiro semestre da Faculdade de Medicina da Universidade Luterana Interna no estágio em Clínica Médica. Email para contato: joaozortea@yahoo.com.br

5. Doutorando do décimo primeiro semestre da Faculdade de Medicina da Universidade Luterana Interna no estágio em Clínica Médica. Email para contato: joysch @hotmail.com
} 
SMF está incluída em um espectro de doenças mediadas pelo sistema imunológico após doenças infecciosas agudas, caracterizada por oftalmoplegia, ataxia e arreflexia, descrita como uma variante da Síndrome de Guillan-Barre, mediada por anticorpos IgG anti-GQ1b. O tratamento da SMF consiste no uso de imunoglobulina específica, com bom prognóstico na recuperação. CONCLUSÃO: Ainda que a SFM seja uma condição rara, encontra-se dentro de um espectro de doenças de extrema importância. Cabe ao profissional de saúde reconhecer a sintomatologia e sinais dessas afecções para garantir manejo adequado e assegurar o melhor desfecho possível, considerando que a SFM tem diagnóstico essencialmente clínico.

\section{Introdução}

A síndrome de Miller Fischer (SMF) é uma desordem rara, com incidência anual de 0,09 casos a cada 100.000 habitantes, caracterizada por oftalmoplegia, ataxia e arreflexia, tendo sido descrita pela primeira vez por Fisher em 1956. Descrevemos um caso de síndrome de Miller Fisher caracterizado pela presença dos sintomas e sinais clássicos da doença.

\section{Relato de Caso}

JSS, 51 anos, feminina, previamente hipertensa, diabética e dislipidêmica, em tratamento. Procurou atendimento em emergência com queixa de visão turva e parestesia em membros superiores iniciados há um dia, seguidos de dificuldade na coordenação dos movimentos de início há seis horas. Ao exame físico inicial, apresentava paresia de abducente a esquerda, pupilas hipofotoreativas, leve dismetria e marcha atáxica, sem mais dados relevantes. Realizados exames complementares que evidenciaram leucocitose significativa de 24.000 leucócitos, sem presença de bastonados e exame qualitativo de urina com bacteriúria intensa, iniciando-se antibioticoterapia. Tomografia de crânio não demonstrou alterações, bem como ressonância magnética com gadolíneo. Sob hipótese de evento isquêmico cerebrovascular, foram realizados ecocardiograma e ecografia com Doppler de carótidas, também sem resultados relevantes. Na exclusão de causa isquêmica, paciente foi transferida para enfermaria, com acompanhamento neurológico. Três dias após o início dos sintomas, apresentava estado mental preservado, disartria leve, oftalmoplegia completa a esquerda, oftalmoparesia a direita, ausência de assimetrias faciais, hipoestesia bilateral em face, força preservada em membros inferiores, arreflexia patelar bilateral, Sinal de Hoffmann ausente bilateral, cutâneo plantar em flexão e marcha atáxica. Com hipótese clínica de Síndrome de Miller Fischer, realizada punção lombar após cinco dias do início do quadro, com resultado compatível. Considerando achados clínicos e exames complementares, iniciou-se tratamento com uso de imunoglobulina. Paciente apresentou melhora importante nos sintomas, recebendo alta hospitalar após 20 dias de internação, com orientação de seguimento ambulatorial. 


\section{Discussão do caso}

A síndrome de Guillain-Barré (SGB), Síndrome de Miller Fischer (SMF) e a encefalite de tronco cerebral de Bickerstaff representam um espectro de doenças mediadas pelo sistema imunológico após doenças infecciosas agudas. Em 1956, Charles Miller Fisher descreveu um caso de aguda polineurite com características de oftalmoplegia, ataxia e arreflexia, descrevendo-a como uma variante da SGB, inclusive com a posterior observação de que pacientes com SMF poderiam desenvolver SGB. Anticorpos IgG anti-GQ1b foram identificados em paciente com SMF e encefalite de Bickerstaff. A descoberta de anticorpos IgG anti-GQ1b apoia ainda mais a visão de que os dois transtornos representam um único espectro da doença. As lesões na síndrome de Fisher e na encefalite de tronco cerebral de Bickerstaff são presumivelmente determinado pela expressão de gangliosídeo GQ1b no sistema nervoso periférico e central humano. Pelas manifestações neurológicas da SMF, há a necessidade de descartar a possibilidade de acidente vascular cerebral, considerando a sua grande prevalência e a possível semelhança das manifestações clínicas, tendo como outros diagnósticos diferenciais as infecções e lesões expansivas de sistema nervoso central. 0 tratamento da SMF consiste no uso de imunoglobulina específica, com bom prognóstico na recuperação do paciente.

\section{Conclusão}

Ainda que a SFM seja uma condição rara, encontra-se dentro de um espectro de doenças de extrema importância. Cabe ao profissional de saúde reconhecer a sintomatologia e sinais dessas afecções para garantir manejo adequado e assegurar o melhor desfecho possível, considerando que, embora tenham que ser descartados seus diagnósticos diferenciais, a SFM tem diagnóstico essencialmente clínico.

\section{Referências}

NOBUHIRO, I.; SHAHRIZAILA, N. Guillain-Barré syndrome, Fisher syndrome and Bickerstaff brainstem encephalitis: Understanding the pathogenesis. In Neurology Asia 2010; 15(3): 203-209

MARCIAL, ES; ALDANA, EEC; EMMANUEL, FG; BENITES RH, ORTA, DSJ. Síndrome de Miller Fischer. Arch. Neurocien, México, 2007, 12(3): 180-182.

ARANY, Z.; KOVACS, T.; SIPOS, I.; BERECZI, D. Miller Fisher syndrome: Brief overview and update with a focus on electrophysiological findings. In European Journal Neurology 2012; 19:15-20, e1-3

FISCHER, M. An unusual variant of acute idiopathic polyneuritis (syndrome of ophthalmoplegia, ataxia and areflexia). In New England Journal of Medicine 1956; 255:57-65

CHIBA, A.; KUSUNOKI, S.; SHIMIZU, T.; KANAZAWA, I.; Serum IgG antibody to ganglioside GQ1b is a possible marker of Miller Fisher syndrome. In Ann Neurol 1992; 31:677-9. 36.

KUSUNOKI, S. Diagnosis, pathogenesis and treatment of Miller Fisher syndrome and related disorders: clinical significance of antigQ1b IgG antibody. In Brain Nerve. 2015 Nov;67(11):1371-6. 
RIBEIRO, BN; SALATA TM; BORGES RS; MARCHIORI E. Posterior reversible encephalopathy syndrome following imunnoglobulin therapy in a patient with Miller-Fisher syndrome - In Radiol Bras. 2016 Jan-Feb;49(1):58-9. 